\title{
Post-normal times: re-thinking the futures of the EU-Africa relationship
}

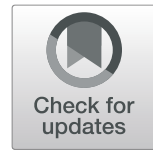

\author{
Robin Bourgeois ${ }^{1,2^{*}}$ (D) Frank Mattheis ${ }^{2,3}$ (D) and John Kotsopoulos ${ }^{2}$ (D)
}

\begin{abstract}
The nature of the relationship between the European Union (EU) and Africa is in permanent evolution. Historically, the EU mostly dominated the relationship while Africa developed adaptive/reactive strategies. With the establishment of new powers as well as efforts to decolonise the thought and practise of North-South interactions, it is crucial to understand what the future of the relationship could be. The purpose of this paper is to draw lessons from the "Broadening the debate on EU-Africa relations" workshop whose aim was to advance perspectives on EU-Africa relations from the point of view of African scholars. The process consisted of identifying major influential factors in the relationship and assessing what role they played in the past and what role they could play in the future. The results indicate a decline of the importance of EU-dominated factors and the emergence of African agency related factors. We interpret these results as a transformation of this relationship, using the concept "post-normal" to highlight indeterminacy, insolvability and irreversibility as the new context. Implications are discussed regarding the type of research that needs to be developed in order to further investigate this transformation, particularly the meaning of a shifting focus from (normal times) EU-Africa relationship to (post-normal times) Africa-EU relationships.
\end{abstract}

Keywords: Africa, European Union, Future, Governance, Post-normal times, EU-Africa, North-South, Decolonisation

\section{Introduction}

The nature of the relationships between the European Union (EU) and Africa is in permanent evolution. From a historical perspective, this evolution has been largely documented [1-3]. Traditionally, the EU mostly dominated the relationship while Africa mainly developed adaptive/ reactive strategies [4]. This relationship took place under a global order based on the pre-eminence of Western powers. Taking into account the current transformations of the global order with the establishment of new powers as well as efforts to decolonise the thought and practise of North-South interactions [5-7], it is crucial to understand what the future of the relationships between the EU and

\footnotetext{
* Correspondence: Robin.bourgeois@cirad.fr

'Unité Mixte de Recherche Acteurs, Ressources et Territoires dans le Développement, Département Environnement et Sociétés, Centre de Coopération Internationale en Recherche Agronomique pour le Développement, 73 rue Jean-François Breton, 34398 Montpellier Cedex 5, France

${ }^{2}$ Centre for the Study of Governance Innovation, University of Pretoria, Old College House, Lynwood Road, Pretoria 0010, South Africa

Full list of author information is available at the end of the article
}

Africa could be [8]. While it is impossible to predict that future, it can be explored to nurture reflection and action.

The purpose of this paper is to stimulate such reflection by drawing lessons from the "Broadening the debate on EU-Africa relations" workshop whose aim was to advance perspectives on EU-Africa relations from the point of view of African scholars in the continent and the wider diaspora. The workshop was the main event of the research project EU-Africa relations in a changing global order (ERGO), which was funded by the European Commission's Jean Monnet programme. The workshop took place in July 2017 at the University of Pretoria, South Africa and was not only a contribution to redressing asymmetry in the imbalance in scholarship in EU-Africa relations but also an effort in challenging Eurocentric interpretations of the EU-Africa relationship. Sessions involving 25 participants (see Additional file 1 Annex 1. Profiles of the participants) from numerous African countries, Europe, and institutions focused on a futureoriented reflection about EU-Africa relationship. As the workshop intended also to provide scholars with an 
opportunity to scrutinize hitherto underexplored dimensions of the relationship, beyond the old, persistent trade and aid structures inherited from the Treaty of Rome and the Lomé Convention, it included future-oriented sessions providing the opportunity to explore these dimensions and reflect on potential evolution of the traditional pattern of relationships. We will argue here that the qualitative shift in positioning the drivers of the relationship between the EU and Africa as observed in the workshop results entails elements that characterize a post-normal situation. This qualitative shift can be associated with a shift of focus from (normal times) EU-Africa relationship to (post normal times) AfricaEU relationship.

This paper presents first the methodology used in the sessions. Results are then presented in the "Results" section. The discussion in the "Interpretation of the results with a post-normal framework" section develops using an analytical framework referring to post-normality. Implications for the future of the relationships are presented in the conclusion ("Implications for further research" section).

\section{Methodology}

\section{Pre-workshop activities}

The workshop was preceded by an open call for contributions that was circulated publicly by the European Studies Association of Sub-Saharan Africa (ESA-SSA), outlining the context and purpose of the format. The two main stated objectives were to begin to redress the underrepresentation of African perspectives in the broader discourse about EU-Africa relations and, by extension, to broaden epistemological approaches to interpreting the relationship. The call explicitly encouraged the participation of scholars from the African continent, though also remaining open to innovative perspectives from outside of the continent. Fifty-two proposals were received and underwent a blind review by three reviewers from ESA-SSA, each detailing their decision to accept, reject or abstain.

All three reviewers unanimously accepted ten proposals and after discussions, they selected another twelve that received two recommendations to be accepted. The selected contributors were invited to join the reviewers for a two-day author workshop in Pretoria, South Africa in 2017, which also included the participation of the ESA-SSA team. All African subregions were represented (one North, one Central, six West, five East and eight Southern) and $40 \%$ of the participants were women. A variety of social science disciplines were represented, with a focus on international relations and political sciences but also including philosophy, education and economics.
Six thematic panels allowed the contributors to present their papers and engage in plenary discussion sessions. After the workshop, the contributors worked further towards preparing for publication by submitting revised and extended versions of their papers. Based on the these submissions ten authors were selected for a second workshop, where the papers were discussed in more detail with the help of a journal editor, before proceeding to the journal double-blind peer review towards a special issue of the South African Journal of International Affairs [9].

\section{Futures methodology}

Preparatory work for the futures session of the workshop consisted in a review of documentation on EU-Africa relationships with the objective to identify factors that have shaped, are shaping, or were expected to shape EUAfrica relationships. More than 60 relevant documents were identified and screened (see Additional file 2 Annex 2). The workshop facilitators prepared a preliminary list of factors for further discussion and completion ("Factors influencing EU-Africa relationship from a literature review" section).

In session 1, participants first reflected on a list of factors in order to adjust them if needed according to their own understanding of the dynamics of the relationship. Then, they allocated individually five red dots to the five factors they considered to have been most influential in the past for the EU-Africa relationship, and five green ones for the five factors they considered would be the most influential in the future for the EU-Africa relationship. Participants subsequently worked in groups and identified surprising result(s), putting each one on a card and sharing them with the other groups. This discussion was intended to enhance the ownership of the results by the group of participants as a whole.

While the number of participants involved in the workshop could be considered "small-N" in terms of test size, the diverse range of participants, the extended time and depth of engagement on the issue of EU-Africa relations, and the novelty of the testing involved, all contributed to rich opportunities for discussion and ultimately observation. This is in line with the assertion that small$\mathrm{N}$ outputs can serve as a complementary tool along a spectrum that includes larger quantitative studies [1012]. Furthermore, the "within case" nature of the workshop-that is, the assessment of the dynamics of the same relationship from a diverse range of perspectivesallowed for a type of pattern-matching [13], where participants could offer different interpretations of EU-Africa relations, even if they were all exposed to the same observable elements of the relationship.

An additional session aimed at using scenarios of alternative world orders [14] and specific drivers of EU- 
Africa relations to stimulate multi-dimensional reflection on the futures of the EU-Africa relationship. Activities consisted of exploring the future through scenario-based group work, sharing results through a "Scenario Fair" and then turning back to the present through a discussion of striking points. The results of this session are not presented here as they do not relate to the core topic of this paper.

\section{Results}

\section{Factors influencing EU-Africa relationship from a literature review}

The literature review of the documents listed in Additional file 2 Annex 2 resulted in the identification of 18 factors influencing EU-Africa relations. These factors were clustered as indicated below into four thematic categories: "Economy", "Power and politics", "Africa agency" and "Europe agency". Below is a breakdown of the factors within each of the categories.

\section{Economy}

1. Financing the operation of the relationship (transactions costs of maintaining engagement, organizing meeting, supporting a Secretariat...)

2. Mutual dependency on each other's markets

3. Level of mutual dependence on each other's critical resources

4. Aid dependency (the extent Africa depends on financial development aid from Europe)

5. Global world order (alternative configurations for the future world governance)

\section{Power and politics}

6. The focus areas of EU-Africa relations (such as geopolitics, society and the environment; institutions; trade and investment; aid)

7. The type of relationship pattern between the EU and Africa (dependency, interdependence, independence...)

8. The level of asymmetry in power relations between the EU and Africa

9. Mutual security dependency (to what extent the EU and Africa depend on each other for their own internal security)

\section{Africa $(A U / A C P)$ agency}

10. The level of African organizational unity as a global partner with EU

11. The level of unity of African views regarding relationships with EU (accounting for regional and member state differences)
12. The nature of the EU-Africa relationship project seen by Africans (e.g. seen through Afrobarometer ${ }^{1}$, through civil society, etc.)

13. The level of development of African entrepreneurship/enterprises

14. Africa's attractiveness relative to other continents in developing relations with Europe

\section{EU agency}

15. The level of European organizational unity as a global partner with Africa

16. The level of unity of European views regarding relationships with Africa

17. Geographical coverage of the EU-Africa relationship (which country/region)

18. Europe's attractiveness relative to other continents in developing relations with Africa

These categories do not constitute exclusive and independent blocks. Figure 1 shows how they interconnect. It displays the EU-Africa relationship as a system of connected dimensions that is embedded in a global world order, which affects each of the four thematic categories. Within this system, the factors related to "Africa agency" and "EU agency" shape simultaneously the factors associated to "Power and politics" and "Economy" and determine post-colonial or neo-colonial patterns. At the same time, the nature of the relationship between $\mathrm{EU}$ and Africa (the large central arrow) shapes their capacity to influence the "Power and politics" and "Economy" factors.

These results are also consistent with trends and drivers identified by [4], namely colonial legacy, partnership, asymmetry, market liberalisation, politicisation, regional actorness and the changing global order.

\section{Shifting perceptions of past and future drivers}

The participants discussed and revised the 18-factor list and decided to include an additional one, under "African agency", namely the role of the African diaspora as a factor that could influence the nature of the relationship in the future. This additional factor echoes the transformation of multilateralism with the inclusion of non-state actors [15].

Table 1 below presents the results of the rating of past and future influences of these 19 factors (see also Additional file 3 Annex 3). The most influential factors in the past are aid dependency (16), the level of asymmetry in power relations (14), and geographical coverage of the EU-Africa relationship (10), followed by the type of relationship pattern between

\footnotetext{
${ }^{1}$ http://www.afrobarometer.org
} 


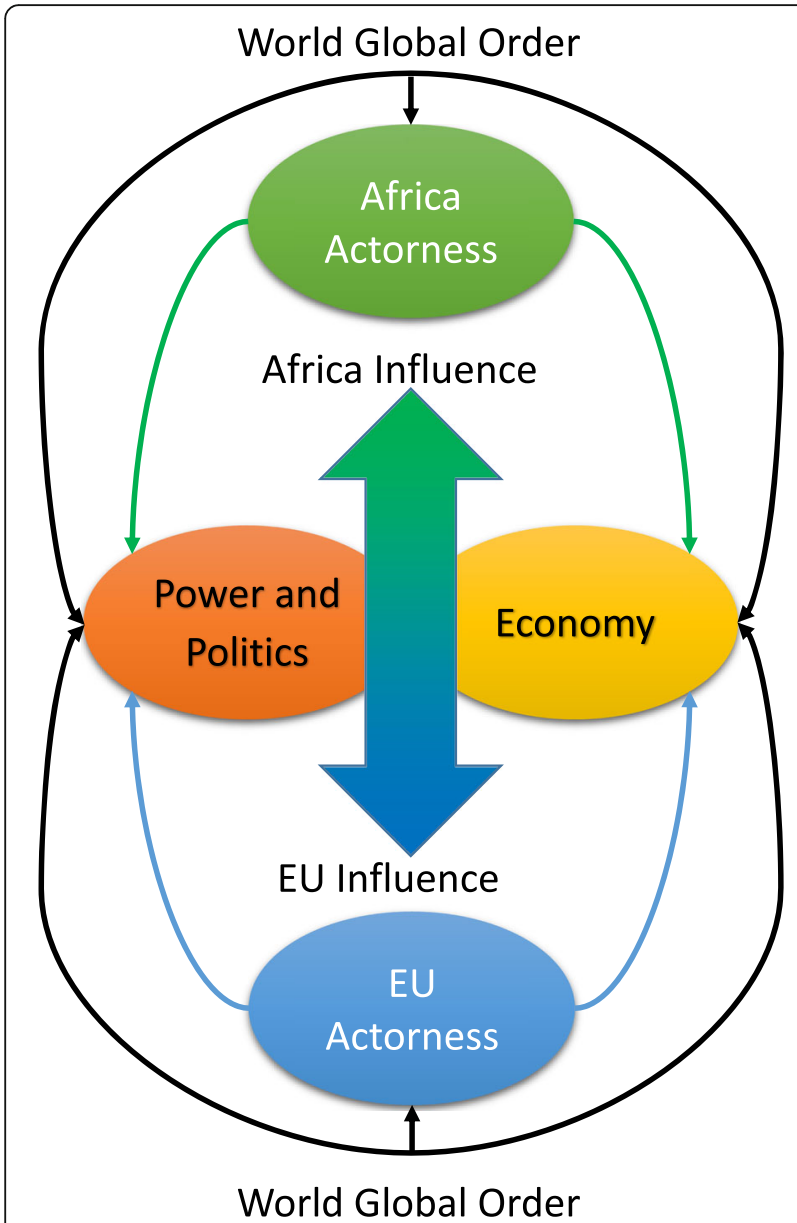

Fig. 1 The EU-Africa relationship in global context. Source: Authors

the EU and Africa (8). A striking point is that none of them belongs to the African agency category. As perceived by the participants, the factors related to African agency are among those with the lowest influence in the past of the EU-Africa relationship, acknowledging the importance of aid dependency and the level of asymmetry of relationships, including economic patterns that favour the exploitation and export of natural resources.

The factors seen as the most influential in the future are mutual security dependency (12), global world order (11), Africa's attractiveness relative to other continents in developing relations with Europe (8), and the level of African organizational unity as a global partner with EU (8). The illustrative point here is that European agency is no longer in the list while African agency is included.

Figure 2 displays the evolution of the influence of these factors from past to future as perceived by the participants. The solid line arrows show which factors are becoming significantly less influent in the future while the dotted arrows show which ones are becoming significantly more influent. They indicate several patterns of transformation. The most striking one is that the complex of drivers (the most influential factors) in the future is significantly different from the complex of drivers in the past. More specifically, six of the seven most influential factors in the past are no longer influential in the future. Moreover, factors related to economy (with exception of Aid dependency) and Africa agency move significantly upwards. Conversely, power and politics (with exception of mutual security dependency) and factors related to European agency, which largely prevailed in the past, are much less influential (if influential at all) in the future.

\section{Interpretation of the results with a post-normal framework}

We argue here that the qualitative shift in positioning the drivers of the relationship between the EU and Africa as observed in the former section entails elements that characterize a post-normal situation. This interpretation will allow us to draw some implications regarding the future of this relationship and the type of research that could be developed in order to further investigate the evolutionary process currently at play.

\section{Post-normal times}

Post-normal times is a concept that has been developed by Sardar [16]. It was drawn from earlier work about the necessity of post-normal science to address situations characterized by uncertainty, value loading and a plurality of legitimate perspectives [17]. Funtowicz and Ravetz [16] observed that in the contemporary world, the nature of change itself was changing and that it required a different approach to grasp it and its implications. Socalled facts were becoming increasingly uncertain and values needed to be considered while stakes were becoming higher and decision more urgent. As Sardar ([18], p435) argues, "the spirit of our age is characterised by uncertainty, rapid change, realignment of power, upheaval and chaotic behavior".

The state of the global world order witnesses such a transformation. Post-normal times as a concept intends to account for a new world order where the "normal" relationships that characterized the post-World War II period are progressively evolving into patterns that are more complex. Heinonen et al. ([19], p1) argue that "digitalisation and globalisation, exacerbating environmental conditions, severe economic challenges, uneven distribution of wealth, and geopolitical crises" are making changes less and less predictable and highlight "surprises as the new normality". This state of the world is the reason why post-normal times are defined using the " $3 \mathrm{Cs}$ " of chaos, complexity and contradiction [16].

The concept of post-normal times is used here with a heuristic perspective in order to analyse the observed changes in social and political dimensions that force us 
Table 1 Perceived past and future influences of the identified factors on EU-Africa relationship

\begin{tabular}{|c|c|c|c|}
\hline & Factors & Past & Future \\
\hline \multirow[t]{5}{*}{ Economy } & Financing the operation of the relationship & 5 & 7 \\
\hline & Mutual dependency on each other's markets & 5 & 6 \\
\hline & Level of mutual dependence on each other's critical resources & 6 & 6 \\
\hline & Aid dependency & 16 & 0 \\
\hline & Global world order & 4 & 11 \\
\hline \multirow[t]{4}{*}{ Power and politics } & The focus areas of EU-Africa relations & 0 & 4 \\
\hline & The type of relationship pattern between the EU and Africa & 8 & 3 \\
\hline & The level of asymmetry in power relations between EU and Africa & 14 & 2 \\
\hline & Mutual security dependency & 1 & 12 \\
\hline \multirow[t]{6}{*}{ African agency } & The level of African organizational unity as a global partner with EU & 2 & 8 \\
\hline & The level of unity of African views regarding relationships with EU & 3 & 5 \\
\hline & The nature of the EU-Africa relationship project seen by Africans & 0 & 1 \\
\hline & The level of development of African entrepreneurship/enterprises & 3 & 6 \\
\hline & Africa's attractiveness relative to other continents in developing relations with Europe & 0 & 8 \\
\hline & The role of the African diaspora & 0 & 7 \\
\hline \multirow[t]{4}{*}{ European agency } & The level of European organizational unity as a global partner with Africa & 6 & 1 \\
\hline & The level of unity of European views regarding relationships with Africa & 7 & 0 \\
\hline & Geographical coverage of EU-Africa relationship & 10 & 2 \\
\hline & Europe's attractiveness relative to other continents in developing relations with Africa & 1 & 5 \\
\hline
\end{tabular}

Source: Authors

to think beyond forecasts, time linearity and trends. It is a needed addition to the hermeneutics of classic, modern and postmodern times, as per Table 2. As such, we use it here for apprehending wicked problems [20], that can be defined as "... a class of social system problems which are ill-formulated, where the information is confusing, where there are many clients and decision makers with conflicting values, and where the ramifications in the whole system are thoroughly confusing" [21]. Wicked problems still resonate today with problem solving preoccupations, particularly in the domain of policy definition and interventions [22].

Alternative approaches to post-normality as indicated in Table 2 do not provide the heuristic framework needed to handle situations of conflicts and contradictions particularly when it comes to addressing an issue of interconnection such as the governance of a relationship anchored in geo-politics. In fact, the current transformation of the relationship is essentially the result of a tension between postmodern, classic, and modern representations still at work.

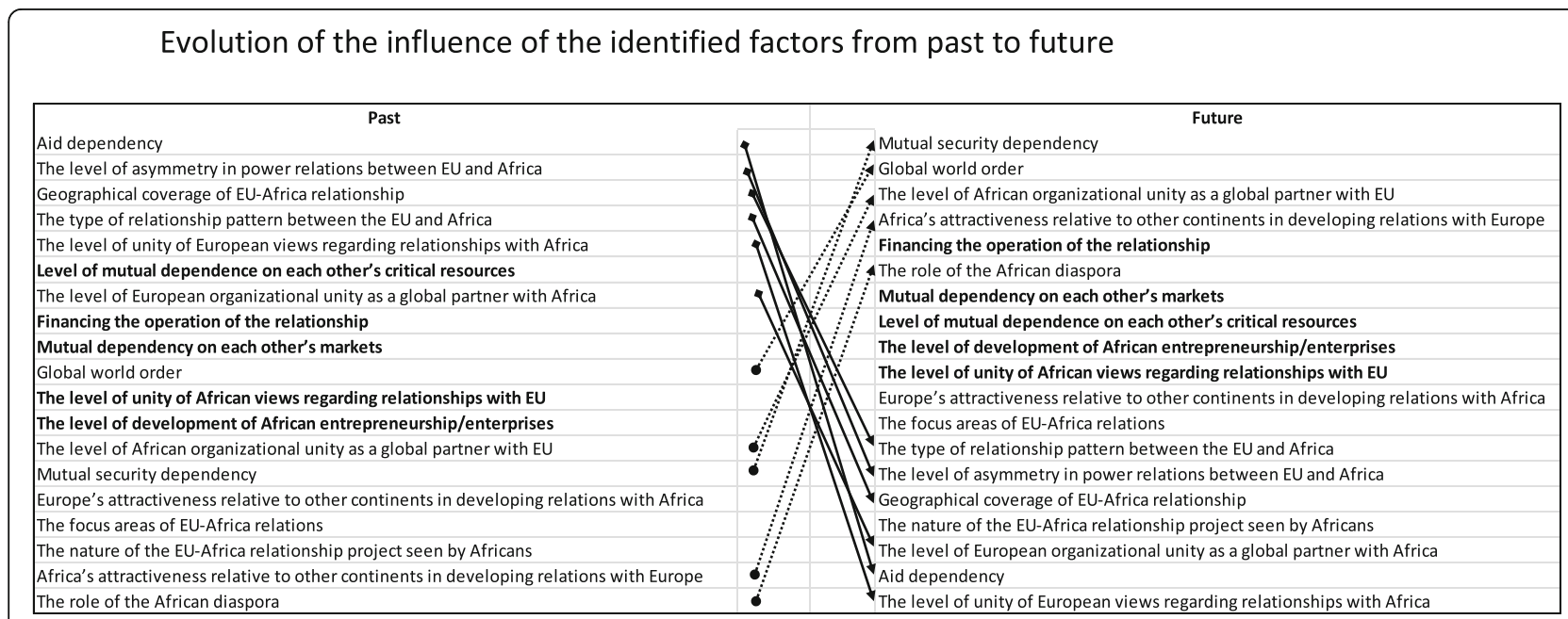

Fig. 2 Evolution of the influence of the identified factors from past to future. Source: Authors 
Table 2 Different perceptions and attitudes towards the world

\begin{tabular}{|c|c|c|c|c|}
\hline & Classic & Modern & Postmodern & Post-normal \\
\hline Meaning & I think therefore I am & I progress therefore I am & I shop therefore I am & I share therefore I am \\
\hline Truth & Defined & Monolithic & Relative & Contradictory \\
\hline Identity & Tradition and culture & Science and technology & Consumption & Connectivity \\
\hline Systems & Simple, closed & Complicated, closed & Complex, open & $\begin{array}{l}\text { Open, chaotic } \\
\text { interconnected }\end{array}$ \\
\hline Key concepts & $\begin{array}{l}\text { Conquest, progress } \\
\text { supremacy, }\end{array}$ & $\begin{array}{l}\text { Progress, efficiency, } \\
\text { modernization }\end{array}$ & $\begin{array}{l}\text { Relativism, plurality, } \\
\text { individuality }\end{array}$ & $\begin{array}{l}\text { Complexity, chaos, } \\
\text { contradictions }\end{array}$ \\
\hline
\end{tabular}

Source: Adapted from the timeline at CPPFS web page: http://postnormaltim.es/essentials

Post-normality helps to incorporate these contradictions and connectivity into a more encompassing representation of the world.

\section{EU-Africa relationship from a post-normal perspective}

At least ten attributes characterize wicked problems [20]. These attributes question the relevance of investigating the future of EU-Africa relationships using the epistemologies of classic, modern or even postmodern science. Among these attributes, it is worth noting some specific ones, namely indeterminacy, insolvability and irreversibility, which we can combine to help in understanding the complexity of the question of the EU-Africa relationship and use to advocate for designing and applying a post-normal science-based approach to the exploration of its futures.

The first combination of these attributes relates to the indeterminacy of the problem. Such indeterminacy results from (i) the fact that there is no definitive formulation about what the problem of the EU-Africa relationship is exactly, (ii) the choice of the explanation determines the nature of the solution, (iii) solutions are not true-or-false, but good-or-bad and (iv) the problem is essentially idiosyncratic.

Indeterminacy is determined by the existence of a diversity of parties that will formulate the problem from their own perspective, will find solutions from their own way of explaining the problem and will judge the solutions from their own varying interests.

In our case, these elements of indeterminacy relate to the asymmetric nature of the relationship. The asymmetry firstly manifests itself in different expectations regarding the economic terms of the relationship (such as trade agreements), the formal terms (such as the recognition as equals partners) and the political terms (such as domestic conditionalities). Secondly, the asymmetry also comprises unequal financial and personnel means to conduct the relationship as well as different positions in the global order. Mackie et al. note that "On the African side, several key strategies have emerged for breaking out of the asymmetrical relationship with the EU: increased political assertiveness through a united African voice, enhanced financial autonomy of the AU and diversification of political and development partners" ([23], p2). This strategy has been employed in two delineations, firstly through the ACP group and more recently through the African Union. Other pathways towards less asymmetry include the reduction of financial dependence on the EU with respect to the implementation of the relationship. The reforms of the AU towards establishing greater financial autonomy for itself and by consequence for its external outreach is a visible sign of this strategy. Another pathway is to increase the diversity of external relations away from the former colonial powers. The increasing relevance of more recently established economic powers such as China for both financial and political support constitutes a context with more competition and potentially more leverage capacity for the African side. Meanwhile, on the European side, the expectations towards the relationship with Africa are also becoming increasingly complex with shorter-term interests related to security and migration issues competing with a value-based foreign policy, guided by a commitment to human rights, democracy and poverty [21]. Although the AU also considers these fields as relevant, the two partners do not necessarily share the same definition of the problem to solve or the policy response formulation.

The asymmetric expectations towards the relationship thus produce a tendency towards diverging objectives, also in relationship with other priorities. For example, the EU's commitments will be shaped by negotiations concerning its general budget and the amount of resources dedicated to Africa-specific interactions and policies will be decided in conjuncture with other priorities, including internal ones. The negotiations with the UK regarding its exit from the EU will also have a secondary effect on the regional focus of the EU's outreach. On the African side, the African Continental Free Trade Area that aims to reduce tariff barriers and increase economic flows will also impact on the position to take vis-à-vis the $\mathrm{EU}$ in trade negotiations.

The second combination relates to the insolvability of the problem which is a result of a combination of the following attributes: (i) there are no stopping rules, (ii) there is no immediate and no ultimate test of a solution 
and (iii) it can be considered a symptom of another problem. Insolvability is determined by the fact that one cannot say when the solution has been found since any answer will trigger waves of problematic consequences due to its implementation, knowing that it will also affect other problems at other scales or in other dimensions.

In the case of the EU and Africa, insolvability can be interpreted in numerous ways, including the perpetual challenge of delimiting what is a hugely complex and multi-layered relationship. What is on the agenda and what is off and who decides? Thematically, for instance, EU-Africa relations have broadened in scope from the trade and aid scope of EU-ACP relations to embrace more political engagement under the auspices of EU-AU relations. This in turn has created jurisdictional overlaps between the Cotonou Agreement and the Joint AfricaEU Strategy (JAES), especially in the area of political dialogue. The often separate or dual track approach to North Africa [24] has further added to the insolvability problem.

The deeply institutional nature of EU-Africa relations also leads to inertia in various forms. Historically, the ability of African recipient countries to absorb European Development Fund support has been an issue [25]. Lately, institutional inertia has led to criticisms of the Cotonou Agreement's insensitivity towards changing dynamics. Mackie et al. point out the disconnect between emerging crises, the division of labour between the AU, RECS and Regional Mechanisms (RM) and non-regional initiatives such as the Multinational Joint Task Force (MNJTF) [23]. The example is indicative of the insolvability characteristic of the blurring of symptoms and solutions.

Uncertainty linked to the insolvability of a problem is not only apparent from the outputs, which show at the same time, the diversity of factors at play and the shifting role the drivers are taking from past to present. It is also apparent in the seven drivers identified by Gatune and Najam that can operate in a positive or negative way depending of what Africans want to do with them [26]. These drivers do not work in isolation but combine into complexes, which can develop in unpredictable ways as they produce unexpected effects, which would feed other unexpected effects elsewhere in the system. They are (based on ([26], p102-107):

Perceptions: how Africa views itself and how it is perceived by others

Governance: type of government and state of political freedom

Knowledge and education: the state of education system and capacity to deliver knowledge
Technology: the social and economic consequences of the state of technological development

Entrepreneurship: capacity to identify and seize economic opportunities

Globalization: the nature of integration of Africa in the world and its consequences

Society: political, economic, and social dynamics within African society

The impact of Chinese competition with Europe in Africa and the replacement of traditional public development investment by private investment is witnessed by the G-20 compact for Africa [24]. It is striking to see that in the Brookings Foresight Africa 2018 report [27], the chapter on "Reassessing Africa's global partnerships" does not mention Europe in the new global order it depicts, even if the share of trade between Africa and the European Union and its member states is acknowledged to be much higher. This is a sign that changes are taking place, putting Africa as a node in a complex network of geopolitical and economic investment.

Finally, there is also an irreversibility attribute associated with wicked problems in the sense that every solution is a one-time operation, meaning that once the solution is implemented, it is impossible to revert to the starting point.

Over the past 60 years, the EU-Africa relationship has become a comprehensive and multi-layered field of interaction. A wide range of institutional mechanisms have been established, for instance through the JAES and the Cotonou Agreement, leading to spill-over effects from the initial focus on aid and trade to other policy areas such as security. At the same time, the EU and the AU have steadily increased their actorness within the relationship, thus become visible, formal and recognised drivers alongside national governments and non-state actors. The manifold policy areas covered in the bureaucratisation of the regional organisations contribute to the stabilisation and consolidation. The institutional frameworks are set out over longer time periods and, although impacted on by political circumstances in one or the other country, constitute fixed points that meet relatively little opposition.

\section{Shifting realities regarding the relationship between} Africa and EU

As per Table 2 above, we focus here on (1) the five drivers that showed the biggest increase in their perceived influence and (2) the five drivers that showed the biggest decrease (Table 3).

From the right column of the table, it appears that the old/conventional relationship that prevailed between Europe and Africa is vanishing. This relationship was characterized by an asymmetry of power in favour of Europe, which shaped the nature of dependency (Africa 
Table 3 Most evolutive drivers of the EU-Africa relationship

\begin{tabular}{ll}
\hline Most increased & Most decreased \\
\hline Mutual security dependency & Aid dependency \\
Global order & The level of asymmetry in power relations between EU and Africa \\
The level of African organizational unity as a global partner with EU & Geographical coverage of EU-Africa relationship \\
$\begin{array}{l}\text { Africa's attractiveness relative to other continents in developing } \\
\text { relations with Europe }\end{array}$ & The type of relationship pattern between the EU and Africa \\
The role of the African diaspora & The level of unity of European views regarding relationships with \\
& Africa \\
\hline
\end{tabular}

Source: Authors

depending on Europe for aid), the geography of the relationship (who would "benefit" from aid) and the pattern of the relationship, all supported by a more or less consistent European position regarding the relationship with Africa. The left column reinforces this, as its elements indicate a shift in the power distribution with the emergence of other sources of power. One source is Africa itself, through its ability to create a unified front on the continent and through the diaspora vis-à-vis Europe. Two other sources are the other partners finding it increasingly more attractive to develop relationships with Africa, and the global order, which may or may not favour intercontinental and interregional relationships.

Yet, there are still a few invariants, that is, factors whose influence does not significantly change (highlighted in bold case in Fig. 2). These are financing the operation of the relationship, mutual dependency on each other's markets, the level of development of African entrepreneurships and enterprises, and the level of unity of African views regarding the relationship with EU. These invariants represent domains where both sides may establish and strengthen a new type of relationship if they wish to. Their continuous presence confirms the transformation of the relationship towards a more balanced distribution of power.

This transformation can be seen as a "normal times" representation of the relationship as EU-Africa relationship being challenged by a rising "post-normal times" representation Africa-EU relationships. This inversion of words does not mean that African perspectives will prevail as the new normal, but symbolizes the need to re-think the relationship as the product of different perspectives.

The normal times of the "EU-Africa relationship" saw a top-down linear influence of the EU, supported by a certain unity of European views about the development of Africa. It explains both the geographic coverage of EU interventions in Africa as well as the type of relations that prevailed and the level of power asymmetry.

Turning around the way the relationship was previously formulated, making it an "Africa-EU relationship", epitomizes its post-normal times nature. A post-normal relationship is characterized by increased diversity in relation to the respective attractiveness of Africa and Europe to other regions as well as a growing interdependency, particularly on security, markets and critical resources. Under the uncertainty of a global order that is becoming more and more unpredictable, Africa's agency in the relationship has new opportunities to grow, particularly through the level of African organizational unity and the role of its diaspora.

\section{Implications for further research \\ Research orientations}

This section intends to derive implications for further research to explore the future of this relationship. If we accept that the Africa-EU relationship witnesses a transformation towards post-normal times situation of "Irreducible complexity, deep uncertainties, multiple legitimate perspectives, value dissent, high stakes, and urgency of decision-making" ([28], p13), leading to indeterminacy, insolvability and irreversibility, then it is logical to advocate for using post-normal science to conduct research on the transformation of this relationship.

One core tenet of post-normal science is the legitimacy of a plurality of perspectives, which challenges existing Eurocentric biases. Under this conception, research is not driven anymore by the search for an absolute truth but by the unveiling of the different aspects of a situation seen from these different perspectives. This substitution of the notion of truth by quality which is at the core of post-normal science is close to the concept of quality that was developed on the patrimonial approach used to solve multi-stakeholder conflicts in using natural resources $[29,30]$. The perspective of each type of stakeholder and their expectations regarding the issue at stake needs to be understood, accounted for and integrated in the process of decision-making. In the case of the EU relationships, this means that research should not only move beyond the European perspective on the relationship-as it was intended with the ERGO project itself-but also to open the dialogue to other legitimate perspectives, from within and outside Africa on the relationships. The outputs of the foresight session of the 
ERGO workshop presented here indicate the value of this opening even if at the small scale of a single workshop.

Another implication of using post-normal science as a research process is to accept that uncertainty and complexity, if not chaos, is the ruling pattern. Therefore, any approach would need to focus on unveiling and exploring uncertainty and complexity rather than reducing uncertainty and simplifying complexity. With regard to research on the future of the relationship, a fruitful stream of investigation would require a transdisciplinary approach as there is no certainty about which dimension would prevail. It would also require a systemic approach as there are no simple linear causality relations between the different dimensions, and therefore what might matter more than what is changing are the effects of changes across the multiple dimensions. This requires exploring recursive loops, self-reinforcing as well as antagonistic and contradictory effects and being open to a plurality of perspectives. Processes of investigation about the future of this relationship need to be open to indeterminacy, inclusion of contingency and disruptive events and dialogue and contradiction.

An important dimension on which post-normal science is based is the concept of "extended peer communities encompassing broader notions of knowledge, uncertainty management, and acknowledgement and management of multiple valid perspectives" [31]. An extended peer community can be broadly defined as "all those with a desire to participate in the resolution of the issue" ([17], p2). Research contributes then to enlarging the space of potential solutions by including societal interactions of this extended peer community into the research process and outputs [32]. Consequently, every stakeholder in the system is legitimate to voice their perception and understanding of the system. Although some central stakeholders, such as business leaders, tend to be less inclined to participate, all are offered the opportunity to contribute directly to new knowledge about the system itself, as the sum of, and interactions between, the different dimensions as they are expressed in that plurality. Research has to unveil these different perspectives, build dialogical spaces for convergence and contradiction and provide a framework that would make it possible to develop a new knowledge that is not only anchored on the observation of facts but also what these observations mean for the potential evolution of the system.

Figure 3 below summarizes what post-normal science means in the context of research on the relationship between Africa and Europe.

\section{A post-normal approach to the futures of EU-Africa relationships}

As a result of this framework for applying post-normal science to Africa-EU relationship as indicated in Fig. 3 above, we designed a research project called "Futures of EU-Africa relations: Lessons from scenario-building" (FEARLESS) that received funding from the European Commission's Erasmus+ Jean Monnet programme from 2017 to 2019.

The FEARLESS research position was that of using anticipation as a post-normal science practice based on the co-elaboration of qualitative scenario [33]. In the light of the recent evolution of the EU-Africa relationship, the project explored the nature of Africa's relations with the European Union in a changing global order, where the EU and its Member States seem to represent a past order, while partnerships with emerging powers China, India and Brazil represent the future. Yet, this assumption is not given. A downturn in growth rates among emerging powers is affecting their engagement with the rest of the world. The EU in the meantime faces

- Focus on "aspects of problem solving that tend to be neglected in traditional accounts of scientific practice: uncertainty, value loading, and a plurality of legitimate perspectives" [17].

- Extended participation in decision-making

- Complexity and uncertainty of natural systems and relevance of human commitments and values

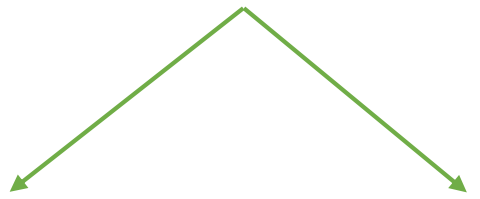

More (African) scholars and decision makers approach AfricaEU relationship from this perspective.
Use anticipation as a post normal science practice: the FEARLESS project (Futures of EUAfrica Relations: LESsons from Scenario building).

Fig. 3 Applying post-normal science to Africa-EU relationship 
many challenges within and at its borders, which have also affected the focus and priorities vis-à-vis Africa.

The impetus here is therefore to explore plausible scenarios of various futures of the relationship. Taking a stance towards exploring uncertainty, complexity and the plurality of alternative voices it explores the main elements affecting the relationship, how do African and European expectations of the future differ or converge, what implication does this have on the requirements for governance?

The research project operated with an extended peer community (EPC) and gave voices to a plurality of views and perceptions calling academics, students, policymakers, practitioners, and other members of civil society to reflect on the futures of EU-Africa relations. Its main activities consisted in providing interactive spaces to the EPC for reflecting, sharing, debating and co-constructing alternative futures for the EU-Africa relationship.

The strong African input in this project is also a reflection of an incrementally changing spirit in EU-Africa relations, which ultimately aspires to be a partnership of equals. This new spirit was reflected in the JAES, which placed new onus on joint responsibility and ownership, precipitating the expansion of the relationship to a variety of new policy areas.

\section{Conclusion}

The results above reveal aspirations for Africa-EU relations that transcend their historical boundaries and embrace post-normal times. This is a vision of a re-adjusted relationship that reflects the long touted, but seldom achieved, aspiration of creating a "partnership of equals". Yet, it does not stop there, project participants consistently reflected a wider sentiment that, at least in relative terms, Africa was increasing in prominence (e.g. economic and demographic expansion) as Europe was decreasing. This was also coupled with acknowledgement of increasing instances of African agency and the expansion of relationships with actors beyond the historic Europe-Africa axis.

Still, the Africa-EU relationship remains encumbered by historical dynamics and persistent asymmetry that act as retardants to change. The world has already entered a post-normal time, but the relationship is still in the transition process. This tension is indicative. By juxtaposing the post-normal results of the ERGO project with many of the resilient and still "normal" features of today's relationship, we are better able to grasp points of friction, including areas of chance and pockets of resistance. Global reference points such as the Sustainable Development Goals of the United Nations can serve as a framework to identify common challenges. However, this collaboration tends to unfold in an asymmetric manner, with Africa being the location of problems and Europe as the source of solutions, rather than in a reciprocal fashion [34].
One key driver identified by workshop participants as diminishing in importance was aid dependency. Indeed, the strengthening of the political dimension of the relationship through the JAES, Cotonou Agreement and ongoing post-Cotonou negotiations, reflects a broader acceptance of the need for broadening and deepening what was once a largely aid and trade focused relationship. However, the EU's International Cooperation and Development program funding has consistently grown over iterations of the European Development Fund (EDF). Renewal of the EDF, set to expire in 2020, will offer an opportunity to re-evaluate the goals and target areas of development funding in the future [35].

At the same time, the level of asymmetry between the two partners-another driver identified as decreasing in importance-has arguably not diminished enough to fully upend the pattern of a relationship circumscribed by decades of history. The Economic Partnership Agreements (EPAs) are the quintessential example of the resilience of asymmetry. The EPAs aimed, among other things, to resolve the inconsistencies that had emerged from the various jurisdictional overlaps between regional organisations on the continent by seeking to align African countries to one EPA group only. The EU sought to do this by circumventing in some instances already established regional groupings, exacerbating frictions in Africa but also reinforcing perceptions of the $\mathrm{EU}$ as imposing its will rather than seeking equitable partnership. The backlash from the African side has been substantial with accusations that the EU was undermining African regionalism, not to mention creating advantageous trade terms for itself [36].

A telling response of the shifting "normal" dynamic has been an ambition of the AU to create a joint African position vis-à-vis Europe and thus break away from the delineation of the ACP and the EPAs. On the EU side, membership is also fluctuating with Brexit in progress and disagreement regarding the accession of countries from the Balkans. These re-configurations have a substantial impact on who is driving the relationship and on how interests and objectives are framed.

The dynamics of the post-Cotonou negotiations are also indicative of this normal/post-normal tension between Africa and the EU-and within the continents and organisations themselves. For instance, there are tensions within Africa itself over the role of the African Union-the apotheosis of Africa's renewed confidence-and the ACP Secretariat, an institution born from a neo-colonial architecture but with its own qualities and expertise. On the EU side, there has been some institutional resistance to pronounced change, with some discussion of modest changes to the current EU-ACP framework, such as a revised continental pillar for the post-Cotonou agreement or a 'single instrument' for EU external action [37]. 
The tensions and friction points in the Africa-EU relationship today are further evidence of a transition from normal to post-normal times. Crucial in the architecture of the relationship for the future is acknowledging the post-normal and not denying uncertainty, complexity and chaos or (re-) imposing a "normal" order where wants and needs are assumed to be universal (and Western). Asymmetry is persistent enough that, at this stage, the EU could still consciously or not impose much of its will on the relationship. This would be antithetical to the post-normal set of circumstances in which we are evidently heading.

\section{Supplementary Information}

The online version contains supplementary material available at https://doi. org/10.1186/s40309-020-00167-8.

Additional file 1: Annex 1. Profiles of the participants

Additional file 2: Annex 2. Literature reviewed for the identification of the drivers of EU-Africa relationship

Additional file 3: Annex 3. Results of the assessment of the role of the identified factors by the participantsx

\section{Acknowledgements}

Not applicable.

\section{Authors' contributions}

RB designed and facilitated the futures workshop and made substantial contributions to the overall structure of the paper, to its introduction, to the presentation of the results and their discussion using post-normality. FM made substantial contributions to the literature review and analysis, cofacilitated the futures workshop and made substantial contributions to the discussion of the results and the final structure of the report. JK made substantial contributions to the literature review and analysis, co-facilitated the futures workshop and made substantial contributions to the conclusion and the final structure of the report. All authors read and approved the final manuscript and have agreed to be personally accountable for the authors' own contributions and to ensure that questions related to the accuracy or integrity of any part of the work, even ones in which they were not personally involved, are appropriately investigated, resolved, and the resolution documented in the literature.

\section{Authors' information}

$\mathrm{RB}$ is a foresight practitioner and senior researcher at the Unité Mixte de Recherche Acteurs, Ressources et Territoires dans le Développement, Département Environnement et Sociétés, Centre de Coopération Internationale en Recherche Agronomique pour le Développement (CIRAD), currently posted at the Centre for the Study of Governance Innovation (Govlnn) in South Africa. His current research activities focus on the futures of governance and the governance of the future, futures literacy as a capability and anticipation as an emancipatory process. He is a member of the World Futures Studies Federation and member of the Editorial Board of the journal "Futures and Foresight Science". He has worked at GFAR in Rome, CAPSA in Indonesia, IICA in Costa Rica and ISNAR in the Netherlands. robin.bourgeois@cirad.fr http://agents.cirad.fr/index.php/Robin+BOURGEOIS https://www.researchgate.net/profile/Robin_Bourgeois ORCID: 0000-0002-1736-3225

FM is a researcher at the Institut d'études européennes (IEE), Université libre de Bruxelles (Belgium) and an associate researcher at the Centre for the Study of Governance Innovation, University of Pretoria (South Africa). He is trained in global studies (MA, PhD) and works on governance structures beyond the nation state in the fields of comparative regionalism and interregionalism. He has been involved in different books on the subject, most recently Fringe Regionalism (Palgrave, 2018) and The Finances of Regional Organisations in the Global South (Routledge, 2019). ftmattheis@gmail.com

ORCID: 0000-0002-8533-5154

JK is an associate fellow at the Centre for the Study of Governance Innovation (GovInn), University of Pretoria, South Africa. He holds a PhD in International Relations (University of Kent, UK) with focus on asymmetrical negotiations between the European Union and Africa.

johnkots@gmail.com

ORCID: 0000-0002-0922-1622

\section{Funding}

This research was supported under the Jean Monnet Activities within the ERASMUS+ programme by the European Union. None of these parties played a role in the design of the study, the collection, analysis, and interpretation of data and in writing the manuscript.

\section{Availability of data and materials}

Not applicable as all relevant data is appended to the main text as Annexes or supplementary Material.

\section{Ethics approval and consent to participate}

Not applicable.

\section{Consent for publication}

Not applicable.

\section{Competing interests}

The authors declare that they have no competing interests.

\section{Author details}

${ }^{1}$ Unité Mixte de Recherche Acteurs, Ressources et Territoires dans le Développement, Département Environnement et Sociétés, Centre de Coopération Internationale en Recherche Agronomique pour le Développement, 73 rue Jean-François Breton, 34398 Montpellier Cedex 5, France. ${ }^{2}$ Centre for the Study of Governance Innovation, University of Pretoria, Old College House, Lynwood Road, Pretoria 0010, South Africa. ${ }^{3}$ Institut d'Etudes Européennes, Université Libre de Bruxelles, Avenue F.D. Roosevelt, 39, 1050 Bruxelles, Belgium.

Received: 7 January 2020 Accepted: 13 October 2020

Published online: 30 October 2020

\section{References}

1. Taylor I (2016) Dependency redux: why Africa is not rising. Rev Afr Political Econ 43(147):8-25. https://doi.org/10.1080/03056244.2015.1084911

2. Carbone M (2013) Between EU actorness and aid effectiveness: the logics of EU aid to Sub-Saharan Africa. Int Relat 27(3):341-355. https://doi.org/10. $1177 / 0047117813497300$

3. Grilli E (1993) The European Community and the Developing Countries. Cambridge University Press, Cambridge

4. Kotsopoulos J, Mattheis F (2018) A contextualisation of EU-Africa relations: trends and drivers from a reciprocal perspective. S Afr J Int Aff. 25(4):445460. https://doi.org/10.1080/10220461.2018.1551154

5. Mlambo A (2006) Western Social Sciences and Africa: the domination and marginalisation of a continent. Afr Sociol Rev 10(1):161-179. www.jstor.org/ stable/afrisocirevi.10.1.161. Accessed 20 Dec 2019.

6. Grosfoguel R (2012) Decolonizing Western Uni-versalisms: decolonial pluriversalism from Aimé Césaire to the Zapatistas Transmodernity. Journal of Peripheral Cultural Production of the Luso-Hispanic World 1(3). https:// escholarship.org/uc/item/01w7163v. Accessed 20 Dec 2019.

7. Comaroff J, Comaroff $J \mathrm{~L}$ (2012) Theory from the South: or, how EuroAmerica is evolving toward Africa. Anthropol Forum 22(2):113-131. https:// doi.org/10.1080/00664677.2012.694169

8. It is useful here to underline the power and perseverance of Pan-Africanism in shaping understandings about the dynamics of Europ-Africa relations. The intellectual antecedents can be traced to the work of W.E. Du Bois, who played an early role in addressing black consciousness and its links to a free Africa. Pan-Africanism grew as a form of identity and, through the works of scholars like Frantz Fanon, explored the psychological effects of colonisation on perceptions - factors that contribute to identity formation to this day. See Rabana (2009) Africana Critical Theory, Lexington Books, Plymouth. 
9. Kotsopoulos J, Mattheis F (eds) (2018) Broadening the debate on EU-Africa relations: towards reciprocal approaches. S Afr J Int Aff. 25(4):445-460. https://doi.org/10.1080/10220461.2018.1551154

10. Hanusch M (2012) African perspectives on China-Africa: modelling popular perceptions and their economic and political determinants. Oxf Dev Stud 40(4):492-516. https://doi.org/10.1080/13600818.2012.728580

11. Keuleers $F(2015)$ Explaining external perceptions: the EU and China in African public opinion. J Common Mark Stud 53(4):803-821. https://doi.org/ 10.1111/jcms.12231

12. Smith PL, Little DR (2018) Small is beautiful: in defense of the small-N design. Psychon Bull Rev 25:2083-2101. https://doi.org/10.3758/s13423018-1451-8

13. Mahoney J (2000) Strategies of causal inference in small-N analysis. Sociol. Methods Res 28(4):387-424. https://doi.org/10.1177/0049124100028004001

14. Bourgeois R, Dixon J, de Haen H, Hubert B, Labbouz B, Treyer S, Wilkinson A (2014) Prospects_Agriculture and rural development assistance in the post-2015 development framework. GDPRD. https:// www.donorplatform.org/publication-agenda-2030/prospects-agricultureand-rural-development-assistance-in-the-post-2015-developmentframework.html. Accessed 20 Dec 2019.

15. Van Langenhove $L$ (2010) The transformation of multilateralism Mode1.0 to Mode2.0. Glob Policy 1(3):262-270. https://doi.org/10.1111/j.1758-5899.2010. 00042.x

16. Sardar Z (2015) Postnormal times revisited. Futures 67:26-39. https://doi.org/ 10.1016/j.futures.2015.02.003

17. Funtowicz S, Ravetz J (2003) Post-normal science. Internet Encycl. Ecol. Econ. http://isecoeco.org/pdf/pstnormsc.pdf. Accessed 20 Dec 2019.

18. Sardar Z (2010) Welcome to postnormal times. Futures 42:435-444. https:// doi.org/10.1016/j.futures.2009.11.028

19. Heinonen S, Karjalainen J, Ruotsalainen J, Steinmüller K (2017) Surprise as the new normal-implications for energy security. Eur J Futures Res 5(12). https://doi.org/10.1007/s40309-017-0117-5

20. Rittel HWJ, Webber MM (1973) Dilemmas in a general theory of planning. Policy Sci 4:155-169. https://doi.org/10.1007/BF01405730

21. Churchman CW (1967) Free for All. Manage. Sci 14(4):B-141-B-142. https:// doi.org/10.1287/mnsc.14.4.B141

22. Crowley K, Head B (2017) The enduring challenge of 'wicked problems': revisiting Rittel and Webber. Policy Sci 50:539-547. https://doi.org/10.1007/ s11077-017-9302-4

23. Mackie J, Ronceray M, Tadesse L (2018) Challenges for Africa-Europe relations a chance to get it right. ECDPM Challenges Paper January 2018. https://ecdpm.org/publications/chance-get-right/. Accessed 20 Dec 2019.

24. De Groof E, Bossuyt J, Abderrahim T, Djinnit D (2019) Looking north and moving south: little enthusiasm for a continent-to-continent approach. ECDPM Discussion Paper 238. https://ecdpm.org/wp-content/uploads/DP23 8-North-Africa-double-pursuit-Part-1-looking-north-moving-south-continentto-continent-ECDPM-January-2019.pdf. Accessed 20 Dec 2019.

25. Ravenhill J (1987) Negotiating the Lomé Conventions: a little is preferable to nothing. In: Zartman I W (ed) positive sum: improving North-South Negotiations. New Brunswick and Oxford: Transaction Books, 213-258.

26. Gatune J, Najam A (2011) Africa 2060: what could be driving the good news from Africa? Foresight 13:100-110. https://doi.org/10.1108/ 14636681111138794

27. Brookings (2017) Foresight Africa 2018-Top Priorities for the Continent in 2018. https://www.brookings.edu/wp-content/uploads/2018/01/foresight-2 018_full_web_final2.pdf.

28. Kønig N, Børsen T, Emmeche C (2017) The ethos of post-normal science. Futures 91:12-24. https://doi.org/10.1016/j.futures.2016.12.004

29. Ollagnon H (1999) Une approche patrimoniale de la gestion de la qualité: une application à la nature et au vivant - Pour une écologie de l'action. Université Paris Panthéon-Sorbonne, Dissertation

30. Pupin V (2008) Les approches patrimoniales au regard de la question de la prise en charge du monde. Dissertation. Institut des Sciences et Industries du Vivant et de I'Environnement. https://pastel.archives-ouvertes.fr/pastel00004920/document. Accessed 20 Dec 2019.

31. Dankel DJ, Vaage NS, van der Sluijs JP (2017) Post-normal science in practice. Futures 91:1-4. https://doi.org/10.1016/j.futures.2017.05.009

32. Giller K E, Leeuwis C, Andersson J A, Andriesse W, Brouwer A, Frost P, Hebinck P, Heitkönig I, van Ittersum M K, Koning N, Ruben R, Slingerland M, Udo H, Veldkamp T, van de Vijver,C. van Wijk M T, Windmeijer P (2008) Competing claims on natural resources: What role for science? Ecol. Soc.
13(2): 34. http://www.ecologyandsociety.org/vol13/iss2/art34/. . Accessed 20 Dec 2019.

33. Bourgeois R, Penunia E, Bisht S, Boruk D (2017) Foresight for all: coelaborative scenario building and empowerment. Technol. Forecast. Soc. Change 124:178-188. https://doi.org/10.1016/j.techfore.2017.04.018

34. Farrell M (2015) Europe-Africa relations over time: History, geopolitics and new political challenges. In: Jorgensen K E, Aarstad AK, Drieskens E, Laatikainen K and Tonra B (eds.) The SAGE Handbook of European Foreign Policy: London, Sage, 794-799.

35. Medinilla A, Bossuyt J (2018) Charting the course to 2020: Fundamental choices for the negotiation of a future ACP-EU partnership. ECDPM. https:// ecdpm.org/wp-content/uploads/Charting-the-course-to-2020-Fundamentalchoices-for-the-negotiation-of-a-future-ACP-EU-partnership-MedinilllaBossuyt-ECDPM.pdf. Accessed 20 Dec 2019.

36. Langan M (2018) Neo-Colonialism and the Poverty of 'Development' in Africa, Palgrave Macmillan. doi: https://doi.org/10.1007/978-3-319-58571-0.

37. Di Ciommo M, Sherriff A, Bossuyt J (2017) The dynamics of EU budget negotiations for external action - Towards a 'single' instrument? ECDPM Briefing Note:99 https://ecdpm.org/publications/dynamics-eu-budgetnegotiations-for-external-action-towards-single-instrument/.

\section{Publisher's Note}

Springer Nature remains neutral with regard to jurisdictional claims in published maps and institutional affiliations.

\section{Submit your manuscript to a SpringerOpen ${ }^{\circ}$ journal and benefit from:}

- Convenient online submission

- Rigorous peer review

- Open access: articles freely available online

- High visibility within the field

- Retaining the copyright to your article

Submit your next manuscript at $\boldsymbol{\nabla}$ springeropen.com 